IZA DP No. 4463

Fiscal Competition for Imperfectly-Mobile Labor and Capital: A Comparative Dynamic Analysis

David E. Wildasin

September 2009 


\title{
Fiscal Competition for Imperfectly-Mobile Labor and Capital: A Comparative Dynamic Analysis
}

\author{
David E. Wildasin \\ University of Kentucky \\ and IZA
}

\section{Discussion Paper No. 4463 \\ September 2009}

\author{
IZA \\ P.O. Box 7240 \\ 53072 Bonn \\ Germany \\ Phone: +49-228-3894-0 \\ Fax: +49-228-3894-180 \\ E-mail: iza@iza.org
}

\begin{abstract}
Any opinions expressed here are those of the author(s) and not those of IZA. Research published in this series may include views on policy, but the institute itself takes no institutional policy positions.

The Institute for the Study of Labor (IZA) in Bonn is a local and virtual international research center and a place of communication between science, politics and business. IZA is an independent nonprofit organization supported by Deutsche Post Foundation. The center is associated with the University of Bonn and offers a stimulating research environment through its international network, workshops and conferences, data service, project support, research visits and doctoral program. IZA engages in (i) original and internationally competitive research in all fields of labor economics, (ii) development of policy concepts, and (iii) dissemination of research results and concepts to the interested public.
\end{abstract}

IZA Discussion Papers often represent preliminary work and are circulated to encourage discussion. Citation of such a paper should account for its provisional character. A revised version may be available directly from the author. 
IZA Discussion Paper No. 4463

September 2009

\section{ABSTRACT \\ Fiscal Competition for Imperfectly-Mobile Labor and Capital: A Comparative Dynamic Analysis ${ }^{*}$}

Interjurisdictional flows of imperfectly-mobile migrants, investment, and other productive resources result in the costly dynamic adjustment of resource stocks. This paper investigates the comparative dynamics of adjustment to changes in local fiscal policy with two imperfectly mobile productive resources. The intertemporal adjustments for both resources depend on complementarity/substitutability in production and the adjustment cost technologies for each, implying that the evaluation of the fiscal treatment of one resource must account for the simultaneous adjustment of both.

JEL Classification: $\quad H 22, H 71, H 87, J 61, R 58$

Keywords: fiscal competition, labor mobility, capital mobility, comparative dynamics

Corresponding author:

David E. Wildasin

Martin School of Public Policy

University of Kentucky

Lexington, KY 40506-0027

USA

E-mail: dew@davidwildasin.us

\footnotetext{
*Presented at a conference "Public Economics: Conference in Honour of Robin Boadway", Kingston, Ontario, May, 2009. This research is an outgrowth of earlier work, versions of which were presented at the International Institute of Public Finance conference on "Fiscal and Regulatory Competition" (Milan, August 2004), at the ASSA meetings, Philadelphia, January 2005, and at the University of Florida. The author is grateful for comments from R. Molzon and from conference participants, especially $D$. Denslow, T. Madies, K. Strumpf, B. Dahlby, and M. Smart, but retains responsibility for errors.
} 


\section{Introduction}

The now-large literature on fiscal competition has emphasized that subnational and national governments do not exist in isolation from the rest of the world but must compete for mobile labor and capital. In what is by now the "benchmark case" for this literature, the focus of attention is on the taxation of a single, mobile factor of production, often interpreted as "capital", by many individual governments in a system of jurisdictions. This basic modeling structure has proven remarkably fruitful as it has been varied, extended, and reinterpreted in many ways (see, e.g., Wilson (1999), Wilson and Wildasin (2004), Wildasin (2006a), for surveys and many additional references.) ${ }^{1}$ The intellectual origins of this literature, perhaps now occasionally forgotten, lie in the study of the incidence of local property taxes the US and elsewhere. In what is still called the "new view" of property tax incidence (see, e.g., Aaron (1975), Zodrow (2007)), building upon seminal work by Mieszkowski (1972), the long-run incidence of local taxes in a closed system of jurisdictions containing a fixed aggregate supply of capital is shown to fall substantially on the system-wide net return to capital. This system-wide perspective differs from an earlier tradition of analysis of the incidence of a property tax imposed by one single locality within a larger ambient economy within which the net rate of return to capital is determined. The taxation of capital by such a community, containing as it does only a "small" fraction of the system-wide stock of capital, would have only a very small impact on the economy-wide net rate of return on capital, and the "old view" of property tax incidence in this context was that the incidence of the tax would fall on local landowners, consumers, workers, or others whose welfare would be adversely affected by changes in the equilibrium prices of local non-traded goods (land rents, non-traded consumption goods including housing, or wages). ${ }^{2}$

\footnotetext{
${ }^{1}$ It goes without saying that many studies have varied the "standard model" in ways that touch upon issues discussed here. For instance, Wilson (1995) examines the problem of choosing multiple policy instruments, de Bartolome (1997) studies the implications of gradual stock adjustment in response to local taxation, and Wildasin and Wilson (1996) study fiscal competition in an overlapping generations model. Makris (2009) studies competition for mobile capital in a model with endogenous savings. Becker and Rauscher (2007) examine an endogenous growth model with interjurisdictional capital mobility where governments provide public inputs to firms.

${ }^{2}$ As noted in an important paper by Bradford (1978), even if a small locality's tax on capital has a very small effect on the system-wide equilibrium net return to capital, this small effect is spread over the system-wide stock of capital, and its
} 
More recently, this modeling approach has been applied to the analysis of corporation income and other source-based taxes on capital income imposed not by small local governments but by nations within the European Union or, indeed, by all nations in a global context. It has also been applied to the analysis of decentralized taxation of labor, whether imposed by local governments, those at the state/provincial level, or, indeed, at the national level. It is directly applicable to the analysis of subsidies to labor and capital, for instance in the context of regional development policy. With modifications, it applies as well to the analysis of decentralized provision of public goods and inputs in an open economy. Still, despite - or perhaps because - of the potentially very wide applicability of the "open economy public economics" models, they do not necessarily lend themselves readily to empirical and policy applications, for at least two reasons.

First, it is clearly essential to determine what factors of production are mobile, and second, it is equally essential to determine over what geographical scope they are mobile. When jurisdictions compete for capital investment, does this competition take place within single metropolitan areas or within states (e.g., Brueckner and Saavedra (2001), Buettner (2001), among states within the US (e.g., Chirinko and Wilson (2007, 2008)), or among countries (e.g., Sorensen (2000, 2004), (Brochner et al. (2007), Devereux and Griffith (2002), Devereux, Griffith, and Klemm (2002))? When they compete for labor, does labor mobility extend to households within a metropolitan area (e.g., Tiebout (1956) and a vast subsequent literature), among school districts (e.g., Nechyba (1999, 2000)), among households within a nation, or among households in the entire world (Wildasin (2006b, 2008)? And does competition take place for all kinds of labor and capital simultaneously, or only for some types, such as highly skilled workers (e.g., Docquier and Rapoport (2008)), welfare recipients (e.g., Peterson and Rom (2000), Brueckner (2003)), highly liquid financial capital (e.g.,, Huizinga and Nicodeme (2004)), manufacturing investment (Chirinko and Wilson (2007, 2008)), old people (Conway and impact on the system-wide net return to capital is of the same order of magnitude - in some cases, is exactly equal to the amount of revenue collected by the locality. Thus, the general-equilibrium effects of policies carried out even by very small localities are not negligible, a finding with far-reaching implications for many aspects of policy analysis. 
Houtenville (2001)), or any other particular categories of capital or investment?

There may be no definitive answers to these questions, but it seems plausible that the degree of mobility for different types of factors of production - i.e, whether or not they are mobile, and over what geographical scope - depends crucially on the time horizon of the analysis. Whereas substantial global flows of "hot money" make occur within a matter of moments, major interregional population shifts seem to occur on time scales ranging from decades to centuries. At the same time, it seems quite important to recognize that factors of production tend to co-locate, presumably at least in substantial part because of complementarities in the production process. For instance, the many buildings and machines that make up major urban agglomerations also have large numbers of people, and regions and nations that experience sustained immigration also generally experience sustained net investment. These considerations suggest that the study of fiscal competition should ultimately be grounded in an explicitly dynamic framework in which more than one factor of production is potentially mobile. Of course, such an approach raises difficult analytical challenges. The goal of the present analysis is to develop a dynamic model of a single open economy that utilizes two imperfectly mobile factors of production - say, labor and capital. The dynamics of the model hinge on the assumption that the inflow or outflow of labor and capital - i.e., migration and investment flows - entail costly adjustment, so that faster adjustment is always potentially possible, but only at greater cost. The equilibrium dynamics imply that endogenously-determined adjustments are not instantaneous.

A model with two imperfectly mobile factors of production permits a more sophisticated approach to the study of many issues relating to fiscal competition than is true of a model with only one mobile factor. In such a setting, fiscal policies that directly affect one mobile resource will also indirectly affect the other mobile resource. As an illustration, suppose that local taxes on capital are reduced, for instance in order to attract investment. If labor is also a mobile resource, and if (in accordance with overwhelming empirical evidence) 
labor and capital are complements, reductions in capital taxation should raise the demand for labor and contribute to an inflow of labor as well as capital. The speed with which these factor co-movements take place is an important part of the allocative consequences of policy changes in such an environment. For example, the output and employment effects of tax cuts for business investment will depend on whether the stock of labor adjusts slowly or rapidly to policy-induced changes in the capital stock. Furthermore, the incidence of such policies, that is, the extent to which different factor owners are helped or harmed by the policies, also depend crucially on the speed of factor adjustment. If the stock of labor adjusts only slowly when business investment increases, workers in the local labor force may enjoy better employment opportunities for a long time following a cut in capital taxes, whereas any increase in their wages will quickly erode if workers from elsewhere arrive quickly to take advantage of improved labor market conditions. For these reasons, the study of the simultaneous dynamic adjustment of the stocks of labor and capital in response to changes in fiscal policies that affect either workers or their employers is a matter of importance for policy evaluation as well as for the political economy of policy determination. These implications are discussed more fully below.

To introduce notation and to establish a benchmark for future reference, the next section of the paper presents a simple static model with two potentially mobile factors of production, briefly recapitulating known results. Section 3 extends this model to an explicitly dynamic framework. The essential analytical tools used here were pioneered by Boadway (1979) in the study of tax incidence in a closed economy, and have been utilized in Wildasin (2003) in a dynamic model of fiscal competition with a single mobile factor of production. Using these tools, comparative dynamic analysis shows how the speed of transition in response to policy changes is determined through dynamic optimizing behavior subject to adjustment costs. Because there are two mobile resources, and because these resources are jointly utilized in the production process, a tax or subsidy on one resource triggers simultaneous dynamic adjustment in the the amounts of both. Section 4 provides quantitative illustrations of the first-order dynamic incidence 
effects of changes in capital and labor taxation. A comparison of the comparative dynamic incidence analysis of Sections 3 and 4 with the comparative statics analysis in Section 2 reveals that fiscal incidence effects can arise in a dynamic setting that have no counterparts, and simply cannot be detected, in a static framework. In particular, in the empirically relevant situation where labor and capital are complementary imperfectly mobile factors of production, a tax (or subsidy) on either will depress (or raise) the gross and net return to the other at all times subsequent to the initiation of the policy change. These "transitory" cross effects of fiscal policy diminish over time and disappear in the long run since, just as in static models, the ultimate long-run incidence of the policy falls on perfectly immobile factors. While the long-run effects of fiscal policy in the dynamic analysis parallel results obtained in static models, transitional cross effects, which arise at any finite time after a change in policy, cannot arise in a standard static models of fiscal competition and can only be observed in a dynamic framework.. The concluding section summarizes briefly and discusses further applications and directions for future research.

\section{Competition for Multiple Factors of Production in a Static Setting}

Consider a small open jurisdiction in which the production process uses one or more completely immobile resources and a vector $k$ of freely-mobile resources to produce either a homogeneous numéraire commodity or, equivalently, many commodities that are freely tradeable on external markets at exogenously-fixed prices. Assuming constant returns to scale with respect to all inputs, output, or the value of output, is a strictly concave function $f(k)$ of the variable inputs alone. Let $\tau$ be a vector of per-unit net fiscal burdens imposed on the mobile resources; for resource $k_{i}, \tau_{i}$ is the sum of all taxes imposed on each unit, net of all cash and in-kind subsidies. The mobile resources are assumed to earn

exogenously-given net rates of return in the external market, denoted by the vector $\rho$. In 
equilibrium, the net return to each mobile resource located within the jurisdiction must be equal to the external net rate of return, i.e., assuming competitive factor markets,

$$
f_{k}-\tau=\rho .
$$

This system of equations determines the vector of equilibrium local employment of the mobile resources as an implicit function $k(\tau)$

$$
\frac{\partial k_{i}}{\partial \tau_{j}}=\frac{F_{i j}}{F}
$$

where $F_{i j}$ is the $i, j$ cofactor of the Hessian matrix of second-order derivatives of the production function $f(k)$ and $F$ is its determinant. By the strict concavity of $f(k)$, $\frac{\partial k_{i}}{\partial \tau_{i}}<0$. In the absence of further restrictions on the production technology, the crossderivatives of $k_{i}$ with respect to other fiscal variables may be of any sign.

Note for future reference that, in the special case where $f_{i j}=0 \quad \forall i, j$, each $k_{i}$ depends only on its own fiscal treatment $\tau_{i}$ and is independent of the policies applied to other factors of production. As one illustration of such a case, suppose that there are several types of freely-mobile labor that work in different traded-goods sectors of the local economy, such as chemical engineers, automotive engineers, and aerospace engineers, each of which combine with immobile, industry-specific capital to produce chemicals, cars, and airplanes. In such a setting, changes in the number of each type of engineer would not affect the productivity of other types. Differences in the fiscal treatment of one type of engineer, such as a tax break for workers in the automotive sector, would have no impact on the demand for other types of workers or on the equilibrium levels of employment or output in other sectors of the economy - that is, all cross-derivatives in (2) are zero. The analysis of fiscal policy in this case can be decomposed, sector by sector, in such a way that the local economy is simply a repeated version of an economy with a single mobile factor of production, subject to a single local fiscal instrument.

More generally, cross-effects arise when different factors of production are complements 
or substitutes. For instance, many macroeconomic models postulate that production is a CES (often Cobb-Douglas) function of labor and capital; in a spatial setting, such production technologies can still be assumed provided that they are extended to take account of the existence of at least one immobile factor of production such as land or natural resources. ${ }^{3}$ Under such assumptions, mobile resources are typically complementary inputs, which implies that favorable fiscal treatment for one increases the equilibrium employment of the others.

As an extreme case, if mobile resources are used in a Leontief or fixed-proportions production technology, every component of $k$ must vary in the same proportion. Choosing units so that input/output ratios are the same for all factors, $\frac{\partial k_{i}}{\partial \tau_{i}} \equiv \frac{\partial k_{i}}{\partial \tau_{j}}<0 \forall i, j$. In this case, there is in effect just one composite variable input whose fiscal treatment is the composite of the net fiscal burdens imposed on each of the nominally distinct variable inputs.

In all of these cases, fiscal burdens imposed on mobile factors of production have zero (or very small) effects on their net returns, which are determined in external markets. From a political economy viewpoint, this means that the owners of mobile resources have no incentive to influence the local political process, whereas the owners of immobile resources do have such incentives. A standard result is that the optimal policy, from the viewpoint of immobile factor owners, is to set the net fiscal burden on mobile resources equal to zero if the set of fiscal instruments is sufficiently rich. ${ }^{4}$

\footnotetext{
${ }^{3}$ If all factors of production are freely mobile and production takes place under constant returns to scale, the global allocation of resources is indeterminate, and, starting from an equilibrium with nonzero output in the local economy, any small change in fiscal policy could result in the departure of all factors of production and the complete collapse of the local economy, a generally uninteresting case.

${ }^{4}$ School districts in the US historically depended very heavily on the local property tax as a source of finance, captured in theoretical models such as Zodrow and Mieszkowski (1986) in the assumption that local taxes on capital are the sole source of local government revenue. Under this assumed restriction on feasible fiscal instruments, immobile residents do not drive the tax rate on freely-mobile capital to zero, since that would imply zero provision of local public goods.
} 


\section{Competition for Mobile Resources with Costly Dynamic Ad- justment}

\subsection{A Dynamic Model}

Following the outline of the static model spelled out above, suppose now that there are adjustment costs associated with changes in the stocks of variable inputs, and that these stocks change gradually over time in response to economic incentives. More precisely, suppose that the value of output within a small open jurisdiction at time $t$ depends on the time-invariant stock of immobile resources and on the stocks of two mobile factors of production, $k_{1 t}$ and $k_{2 t}$, as given by the strictly concave function $f\left(k_{t}\right)$, where $k_{t}=$ $\left(k_{1 t}, k_{2 t}\right)$ is the vector of local stocks of the mobile inputs. Let $f_{i}\left(k_{t}\right)>0$ denote the value of the marginal product of variable factor $i$ and let $f_{i j}\left(k_{t}\right)$ denote the cross-partial derivatives of $f\left(k_{t}\right)$. The matrix $\left[f_{i j}\right]$ is negative definite, i.e., $f_{i i}<0<F \equiv\left|\left[f_{i j}\right]\right|$. Assuming that production takes place under conditions of constant returns to scale with respect to all inputs, the marginal product of the immobile resource(s) is $f\left(k_{t}\right)-f_{k}\left(k_{t}\right) k_{t}$, where $f_{k}\left(k_{t}\right)$ is the vector of marginal products for the variable inputs.

In the present section, the two mobile factors of production are called "capital" (of types 1 and 2, respectively) as a matter of terminological and notational convenience, although the choice of the letter $k$ to denote each of the two mobile inputs is made for notational economy, not to imply that both inputs must be literally be "capital". The two inputs, for instance, could just as well be different types of labor. These inputs can be purchased by local producers at prices that are taken as given by agents within a single small open locality; given that these prices are determined in external markets, units of measurement may be chosen so that one unit of each input has a price of unity. In the case where input $i$ is a capital good, it may be thought of as a non-consumption use of the allpurpose numéraire commodity, as in standard macroeconomic and growth models. In the case where input $i$ is some type of labor, the fixed price should be interpreted as the 
externally-given net wage rate for that type of labor. The normalized fixed input prices, set equal to unity here, correspond to the exogenously-determined vector $\rho$ in the static model of Section 2.

The stock of each input evolves over time according to

$$
\dot{k}_{i t}=\left(g_{i t}-\delta_{i}\right) k_{i t}, i=1,2
$$

where $g_{i t}$ is the rate of "gross investment" and $\delta_{i}$ is a constant exponential rate of "depreciation." These terms have their customary meaning when input $i$ is capital. If input $i$ is some type of labor, however, $g_{i t}$ is more correctly described as a "net migration flow" and $\delta_{i t}$ would be a constant exponential rate of "natural decrease."

Producers in the local economy are perfectly competitive firms that maximize the present value of profits, discounted at the externally-given net rate of return on "financial" capital $r .^{5}$ At each point in time, firms choose the level of employment of immobile resources and the rates of investment for each type of capital. It is costly to adjust the stocks of capital, with $c_{i}\left(g_{i t}\right)$ denoting the cost of adjustment of capital of type $i$ per unit of capital; the adjustment cost functions are assumed to be nonnegative, strictly increasing, and strictly convex in the rate of investment: $c_{i}^{\prime}\left(g_{i t}\right)>0<c_{i}^{\prime \prime}\left(g_{i t}\right)$ with $c_{i}(0)=0 .^{6}$

The cash flow of a representative firm at time $t$ is the value of its output, less its expenditures on investment, less adjustment costs, less any net time invariant fiscal burdens imposed on these stocks $\tau \equiv\left(\tau_{1}, \tau_{2}\right)$, less payments to the owners of immobile factors $w_{t}$. Fiscal policies are assumed to be time-invariant, which greatly simplifies the analysis but of course limits its scope as well. ${ }^{7}$

\footnotetext{
${ }^{5}$ The return $r$ on "financial" capital should be interpreted as an interest rate at which intertemporal trades can be made on external markets. This is to be distinguished from the use of the numéraire commodity as a real capital input in the local production process.

${ }^{6}$ This is a standard specification in models of investment; see, e.g., Hayashi (1982). If input $i$ is interpreted as a type of labor, however, "adjustment costs" should be thought of as "migration costs". If firms reimburse workers for the costs of relocation, then $c_{i}\left(g_{i t}\right)$ denotes the cost per unit of migration, expressed as an increasing and convex function of the rate of migration. If workers must pay all of the migration costs, then $c_{i}\left(g_{i t}\right)$ should be interpreted as a compensating wage differential paid to workers to offset their migration costs. If migration costs are split between firms and workers, the adjustment cost function reflects the sum of migration costs paid by firms plus the compensating wage differential required by migrating workers.

${ }^{7}$ The analysis of the time-invariant case is a useful precursor to more general cases, some of which are discussed in Wildasin (2003). The present investigation abstracts from issues of time consistency and the evolution of policies over
} 


$$
\pi_{t}=f(k)-\sum_{i}\left(g_{i t}+c_{i}\left(g_{i t}\right)\right) k_{i t}-\tau k_{t}-w_{t}
$$

and hence the present value of profits is given by

$$
\Pi=\int_{0}^{\infty} \pi_{t} e^{-r t} d t
$$

Necessary conditions for the maximization of $\Pi$ subject to (3) can be expressed in terms of the current value Hamiltonian

$$
H_{t} \equiv \pi_{t}+\sum_{i} \lambda_{i t}\left(g_{i t}-\delta_{i t}\right) k_{i t}
$$

as

$$
\begin{aligned}
\frac{\partial H_{t}}{\partial g_{i t}}=0 & \leftrightarrow \lambda_{i t}=1+c_{i}^{\prime}\left(g_{i t}\right) \\
-\dot{\lambda}_{i t}+r \lambda_{i t}=\frac{\partial H_{t}}{\partial k_{i t}} & \leftrightarrow-\dot{\lambda}_{i t}=f_{i}\left(k_{t}\right)-c_{i}\left(g_{i t}\right)+\left(\lambda_{i t}-1\right) g_{i t}-\tau_{i}-\lambda_{i t}\left(r+\delta_{i}\right)
\end{aligned}
$$

for $i=1,2$.

Equation (7) determines $g_{i t}$ implicitly as a function of $\lambda_{i t}, \phi_{i}\left(\lambda_{i t}\right)$, satisfying $\phi_{i}^{\prime}\left(\lambda_{i t}\right)=$ $1 / c_{i}^{\prime \prime}>0$. Substituting into (8) and defining $\Psi_{i}\left(\lambda_{i t}\right) \equiv c_{i}\left(\phi_{i}\left[\lambda_{i t}\right]\right)-c_{i}^{\prime}\left(\phi_{i}\left[\lambda_{i t}\right]\right) \phi_{i t}\left(\lambda_{i t}\right)$ yields

$$
-\dot{\lambda}_{i t}=f_{i}\left(k_{t}\right)-\Psi_{i}\left(\lambda_{i t}\right)-\tau_{i}-\lambda_{i t}\left(r+\delta_{i}\right)
$$

for $i=1,2$. Note that $\Psi_{i}^{\prime}=-\phi_{i} c_{i}^{\prime \prime} \phi_{i}^{\prime}=-\phi_{i}$. Equations (3) and (9) form a 4-equation dynamical system in the variables $\left(k_{t}, \lambda_{t}\right)$ with boundary conditions

$$
\begin{aligned}
k_{i 0} & =K_{i 0} \\
\lim _{t \rightarrow \infty} \lambda_{i t} & \equiv \lambda_{i \infty}=\phi_{i}^{-1}\left(\delta_{i}\right)
\end{aligned}
$$

time, though obviously these must be incorporated in a complete analysis (Kehoe (1989)). 
for $i=1,2$ and with a unique steady state satisfying

$$
\begin{aligned}
g_{i \infty} & \equiv \phi_{i}\left(\lambda_{i \infty}\right)=\delta_{i} \\
f_{i}\left(k_{\infty}\right) & =\Psi_{i}\left(\lambda_{i \infty}\right)+\tau_{i}+\lambda_{i \infty}\left(r+\delta_{i}\right)
\end{aligned}
$$

where $K_{i 0}$ denotes a fixed initial stock of $k_{i}$ and where subscript $\infty$ denotes a steady-state value.

\subsection{Policy Impacts on Mobile Resources: Short Run, Long Run, and Tran- sitional}

In order to see how changes in fiscal policy affect the equilibrium capital stocks, differentiate equations (3) and (9) with respect to one of the policy instruments, $\tau_{j}$, to obtain the "variational equations" (see Boadway (1979) and the appendix for additional discussion)

$$
\begin{aligned}
& \frac{d \dot{k}_{i t}}{d \tau_{j}}=\left(\phi_{i}\left(\lambda_{i t}\right)-\delta_{i}\right) \frac{d k_{i t}}{d \tau_{j}}+k_{i t} \phi_{i}^{\prime}\left(\lambda_{i t}\right) \frac{d \lambda_{i t}}{d \tau_{j}} \\
& \frac{d \dot{\lambda}_{i t}}{d \tau_{j}}=-f_{i k}\left(k_{t}\right) \frac{d k_{t}}{d \tau_{j}}+\left(r+\delta_{i}+\Psi_{i}^{\prime}\left(\lambda_{i t}\right)\right) \frac{d \lambda_{i t}}{d \tau_{j}}+\Delta_{i j}
\end{aligned}
$$

where $\Delta_{i j}$ is the Kronecker delta and where $f_{i k}=\left(f_{i 1}, f_{i 2}\right)$.

The solution of these equations is simplified by assuming that the system is initially in a steady-state equilibrium, conditional on some initially-given policies $\left(\tau_{1}, \tau_{2}\right)$ - that is, given these policies, the stocks of both mobile inputs have fully adjusted to their "long run" levels at which firms set each $g_{i t}$ such that $\dot{k}_{i t}=0$ for $i=1,2{ }^{8}$ The steady-state assumption means this system of four first-order linear differential equations in $d \lambda_{t} / d \tau_{j}$ and $d k_{t} / d \tau_{j}$ has constant coefficients. In a steady state, $\Psi_{i}^{\prime}=-\delta_{i}=-\phi_{i}$ and (13) can be written as

$$
\frac{d \lambda_{i t}}{d \tau_{j}}=\frac{c_{i}^{\prime \prime}\left(\delta_{i}\right)}{k_{i \infty}} \frac{d \dot{k}_{i t}}{d \tau_{j}}
$$

\footnotetext{
${ }^{8}$ This is the dynamic analog to the standard assumption, used in comparative statics analyses of models like those in Section 2, that the system is initially in a static equilibrium that is then perturbed by a policy change, producing (2).
} 
from which it follows that

$$
\frac{d \dot{\lambda}_{i t}}{d \tau_{j}}=\frac{c_{i}^{\prime \prime}\left(\delta_{i}\right)}{k_{i \infty}} \frac{d \ddot{k}_{i t}}{d \tau_{j}} .
$$

Using (15) and (16), terms in (14) involving $\lambda_{i t}$ can be eliminated to produce a system of two second-order differential equations in the variables $d k_{i t} / d \tau_{j}$.

This system must satisfy the boundary conditions

$$
\begin{aligned}
\frac{\partial k_{i 0}}{\partial \tau_{j}} & =0 \quad i, j=1,2 \\
\frac{\partial k_{i \infty}}{\partial \tau_{j}} & =\Delta_{i j}\left(\frac{f_{j j}}{F}\right)+\left(1-\Delta_{i j}\right)\left(\frac{-f_{j i}}{F}\right), i, j=1,2, i \neq j
\end{aligned}
$$

where $\partial k_{i \infty} / \partial \tau_{j} \equiv \lim _{t \rightarrow \infty} \partial k_{i t} / \partial \tau_{j}$. The first of these reflects given initial stocks of inputs, and the second is obtained from equations (12).

The boundary conditions describe the short-run and long-run effects of changes in fiscal policy on the amounts of mobile factors of production employed in the local economy:

Proposition 1: (a) An increase in the net tax burden on any mobile resource decreases its long-run equilibrium level, i.e., $\partial k_{i \infty} / \partial \tau_{i}<0$;

(b) an increase in the net tax burden on a mobile resource reduces the long-run equilibrium level of the other mobile factor if the two inputs are complements in the production process, but increases the equilibrium level if they are substitutes, i.e., $\operatorname{sgn}\left(\partial k_{i \infty} / \partial \tau_{j}\right)=$ $-\operatorname{sgn}\left(f_{j i}\right)$ for $i \neq j$.

(c) the long-run comparative-dynamic responses of mobile resources to changes in fiscal policies depend only on the properties of the production technology and are not (directly) affected by adjustment costs.

The results in (17) are identical in form to those obtained in the static model of Section 2, as shown in (2). In particular, the properties of the adjustment cost technology do not affect the comparative steady-state effects of fiscal policy. ${ }^{9}$ The dynamic model thus

\footnotetext{
${ }^{9}$ To be clear, this is only true of the form of the results that appear in (2) and (17).
} 
encompasses, at its extremes, a "short-run" in which no resources are mobile and a "longrun" in which equilibrium stocks of mobile resources adjust exactly as predicted in the static model.

While it is important to understand the short and long run effects of policy changes, much of the important impact of policy - in fact, the entire impact, other than the most transitory effects and the effects that are only realized asymptotically - occurs during the transition from the short to the long run.

This transition, and in particular the equilibrium speed of adjustment, depends on the adjustment cost technology, as can be seen from the four characteristic roots of the system derived from (13)-(16)

$$
\frac{r}{2} \pm \frac{\sqrt{b_{1} \pm 2 \sqrt{b_{2}}}}{2}
$$

where

$$
\begin{gathered}
b_{1} \equiv r^{2}-2\left(\frac{k_{1} f_{11}}{c_{1}^{\prime \prime}}+\frac{k_{2} f_{22}}{c_{2}^{\prime \prime}}\right) \\
b_{2} \equiv\left(\frac{k_{1} f_{11}}{c_{1}^{\prime \prime}}-\frac{k_{2} f_{22}}{c_{2}^{\prime \prime}}\right)^{2}+4 \frac{k_{1} f_{12}}{c_{2}^{\prime \prime}} \frac{k_{2} f_{21}}{c_{1}^{\prime \prime}} .
\end{gathered}
$$

Concavity of the production function and convexity of the adjustment cost functions imply that (i) $b_{1}>r^{2}$ and $b_{2}>0$, so that $b_{1}+2 \sqrt{b_{2}}>r^{2}$, and (ii) $b_{1}-2 \sqrt{b_{2}}>0$. Hence, all roots are real, with two positive and two negative roots.

The boundary conditions imply that only terms involving the negative roots appear in the solutions to these equations. Specifically, defining $\gamma_{1} \equiv r-\sqrt{b_{1}+2 \sqrt{b_{2}}}$ and 
$\gamma_{2} \equiv r-\sqrt{b_{1}-2 \sqrt{b_{2}}}$, these solutions are $\operatorname{arc}^{10}$

$$
\begin{aligned}
\frac{\partial k_{i t}}{\partial \tau_{i}} & =\frac{\partial k_{i \infty}}{\partial \tau_{i}}\left(1-\frac{e^{\frac{1}{2} \gamma_{1} t}+e^{\frac{1}{2} \gamma_{2} t}}{2}\right) \\
& +\left(\frac{k_{i \infty}}{c_{i}^{\prime \prime}}\left[\frac{F-f_{12} f_{21}}{F}\right]-\frac{k_{j \infty}}{c_{j}^{\prime \prime}} \frac{f_{j j}^{2}}{F}\right)\left(\frac{e^{\frac{1}{2} \gamma_{1} t}-e^{\frac{1}{2} \gamma_{2} t}}{2 \sqrt{b_{2}}}\right) \\
\frac{\partial k_{i t}}{\partial \tau_{j}} & =\frac{\partial k_{i \infty}}{\partial \tau_{j}}\left(\left[1-\frac{e^{\frac{1}{2} \gamma_{1} t}+e^{\frac{1}{2} \gamma_{2} t}}{2}\right]+\left[\frac{k_{1 \infty}}{c_{1}^{\prime \prime}} f_{11}+\frac{k_{2 \infty}}{c_{2}^{\prime \prime}} f_{22}\right]\left[\frac{e^{\frac{1}{2} \gamma_{1} t}-e^{\frac{1}{2} \gamma_{2} t}}{2 \sqrt{b_{2}}}\right]\right) \\
& =\frac{\partial k_{j t}}{\partial \tau_{i}} .
\end{aligned}
$$

To interpret these results, note first that the expression $1-\left(e^{\gamma_{1} t}+e^{\gamma_{2} t}\right) / 2$ appears in the leading terms in each equation. At $t=0$, this expression is equal to 0 , and it approaches 1 as $t \rightarrow \infty$. The expression $e^{\gamma_{1} t}-e^{\gamma_{2} t}$ appears in the trailing terms in (21) and (22) and is 0 at $t=0$. Because $\gamma_{1}<\gamma_{2}<0$, it is negative for all $t>0$ and approaches zero as $t \rightarrow \infty$. These remarks verify that the solutions satisfy the boundary conditions (17). In economic terms, this means that the key results from the static model of Section 2 are confirmed in the long run.

In the special case where $f_{i j}=0$, changes in the stock of one factor have no effect on the productivity of the other factor; in effect, each factor of production is specific to a different sector. Intuitively, a tax on one factor should have no effect on the other in this special case, whether temporarily or in the long run. This is confirmed by (22) since the multiplicative term corresponding to the boundary condition is zero. Detailed calculations (available on request) also show that the solution (21) reduces to

$$
\frac{\partial k_{i t}}{\partial \tau_{i}}=\frac{1}{f_{i i}}\left(1-e^{\frac{1}{2}\left[r-\sqrt{r^{2}-4 \frac{k}{c_{i}^{\prime \prime}} f_{i i}}\right] t}\right)
$$

in this special case, confirming that the response of the taxed factor depends on its own adjustment cost and on the elasticity of demand for this factor alone and not on the

\footnotetext{
${ }^{10}$ The computation and verification of these solutions are in principle straightforward but involve many detailed calculations. Perhaps most important and least obvious are the derivations that allow for the signing and ordering of the characteristic roots. These details, omitted here for brevity, are available to interested readers on request.
} 
corresponding terms for the other factor. In effect, the analysis reduces in this case to the case of a single mobile factor already analyzed elsewhere (Wildasin (2003)).

In the general case where $f_{i j} \neq 0$, however, the above solutions show that the adjustment of the two factor stocks is interdependent, both during the transition to a new steady state and in the long run, as expected. The roots $\gamma_{i}$ determine the speed of adjustment of the mobile factors and, as shown in (18)-(20), these depend on the convexity of the adjustment cost functions. If the $c_{i}^{\prime \prime}$ terms are small, the roots are large in absolute value, which means that the speed of adjustment of the system is rapid. The intuition is straightforward: if high rates of adjustment are not much more costly (at the margin) than low rates, there is little incentive to defer adjustment to policy changes. On the other hand, if (marginal) adjustment costs rise steeply as the rate of adjustment increases, there is a significant cost savings to be realized by adjusting factor stocks slowly. Because both roots enter into the solutions (21) and (22), the speed of adjustment of each variable input depends not only on its own adjustment cost technology, but on the adjustment costs for the other input: the two are interdependent, as again should be expected.

\subsection{The Dynamic Incidence of Taxes on Mobile Factors}

Because (21) and (22) spell out the comparative dynamic response of equilibrium factor stocks to changes in tax policy, they can be used to determine the responses of all other variables in the system that depend on these stocks. Of particular interest from a public finance perspective is the dynamic incidence of tax policy. In the long run, the net returns to both of the mobile factors of production are unaffected by changes in local tax policy, since both factors must eventually earn the unchanged external net rate of return. The gross factor prices for both factors depend on their stocks, however, both in the short and the long run, and, at the moment that a tax change takes place, these stocks are fixed. An increase in the tax on factor $i$ therefore immediately reduces the net return to this factor by the amount of the tax, i.e., the short-run incidence of a tax on an imperfectly mobile 
factor falls entirely on that factor. Because factor stocks cannot adjust instantaneously to changes in policy, the gross and net returns to the other imperfectly mobile factor $j$ and to the completely immobile factors are initially unaffected by an increased tax on factor $i$. In the short run, in other words, there is no shifting of the tax on the imperfectly mobile taxed factor, even though the entire burden of the tax can only fall on the completely immobile factor of production in the long run (ignoring, that is, the small but not zero effect of local taxes on external factor prices, à la Bradford (1978)).

The incidence of the tax during the transition to a new steady state depends on whether factors $i$ and $j$ are complements, substitutes, or independents in production. In the latter case, the return to factor $j$ is completely unaffected by a change in taxation on factor $i$ in the short run, during the transition to the new steady state, and in the long run. If the two factors are complements, an increased tax on factor $i$ triggers an initial reduction in the gross and net return to that factor, giving rise to a reduction of the stock of that factor that gradually raises its gross and net return back to their long-run values. During this transition, the burden of the tax on factor $i$ is partially shifted to factor $j$, even though there is no initial effect nor any long run effect. If factors $i$ and $j$ are substitutes $\left(f_{i j}<0\right)$, then an increase in the tax on $i$ raises the gross and net return to factor $j$ during the transition to a new steady state.

A static analysis of the type presented in Section 2 shows that a tax on a mobile factor of production falls entirely on that factor in the short run (i.e., before factor stocks can adjust to the tax) and that the tax is entirely shifted to the completely immobile factor of production in the long run, with no effect on other factors of production either in the short or the long runs. The preceding comparative dynamic analysis confirms these results, but it also shows that increased taxation of one imperfectly mobile factor of production imposes a burden on a complementary imperfectly mobile factor of production during the transition to a new steady state and that it confers a benefit to such a factor if it is a substitute in production for the taxed factor. These effects cannot be discerned in a 
comparative static analysis such as that of Section 2.

\section{Illustrative Calculations}

A limitation of the analysis presented above, like that of standard tax incidence analyses based on comparative statics calculations (e.g., in the tradition of the Harberger model), is that it only shows the first-order effects of a change in tax policy. Computable general equilibrium (CGE) analyses overcome this limitation by postulating explicit forms for production functions and other elements of the model, making it possible to compute explicitly the impacts of discrete policy changes on equilibrium values of relevant variables. As against this advantage of CGE modeling, of course, the validity of the assumed function forms, not only as local approximations but over discrete ranges, is always open to question. Analysis of the first-order impacts of policy changes thus complements the analysis of discrete changes via CGE models.

Similar consideration apply in dynamic analysis. With explicit specifications of functional forms for production and adjustment cost functions, it would be possible to calculate dynamic general equilibria for the model presented above and thus to calculate explicitly the dynamic impact of discrete policy changes. The preceding analysis, on the other hand, provides first-order approximations to the effects of policy changes without imposing assumptions about functional forms.

It is also possible to combine these two approaches by imposing specific functional forms which are assumed to be locally valid; with information about parameter values, it is then possible to calculate the first-order impacts of policy changes. This approach is still limited to first-order approximations, i.e., to rates of change in response to policy changes rather than to calculation of discretely different equilibrium paths for discretely different policies. On the other hand, it does not require that the postulated functional forms be valid over wide ranges, possibly beyond the range of empirical observation. 
To illustrate this approach, and to provide some sense of the quantitative implications of the comparative dynamic responses to fiscal policy changes, let us assume that the production function is locally well approximated by a Cobb-Douglas function of the immobile factor and of the two imperfectly mobile factors such as capital and labor. Within the context of the model, capital and labor may be distinguished by their shares in the value of production, which are assumed to be 0.2 and 0.6 resp., implying a factor share for the immobile factors - call them "land", in aggregate - of 0.2. In calculating the solutions (21) and (22) numerically, it is convenient to assume $k_{i \infty}=1$ for $i=1,2$. The choice of an interest rate $r$ amounts essentially to the choice of unit of time; $r=0.03$ is a reasonable value for an annual interest rate.

Once relevant parameter values are specified, it is possible to calculate numerically the values of the derivatives in (21) and (22). Details of these calculations are omitted to save space, but they show that increased fiscal burdens on either capital or labor trigger reductions in both, as expected given that they are complements. The speeds of adjustment of these stocks of course depend on the adjustment cost parameters, and in the expected directions. If the values $c_{1}^{\prime \prime}=5$ and $c_{2}^{\prime \prime}=1$ are assumed, most of the response to changes in the fiscal treatment of capital and labor occurs within the first half-decade of a policy change; in the absence of established empirical estimates for such parameters, these are taken as plausible baseline values.

Although factor stock adjustments are of fundamental importance in the model, the impact of taxes on factor prices is of greater economic interest. Denoting the gross returns to capital and labor by $R_{t}$ and $W_{t}$ respectively, and letting capital be factor 1 , the time paths of changes in gross factor prices in response to a change in capital taxation are given by

$$
\frac{d R_{t}}{d \tau_{1}}=f_{1 k} \frac{d k_{t}}{d \tau_{1}} \text { and } \frac{d W_{t}}{d \tau_{1}}=f_{2 k} \frac{d k_{t}}{d \tau_{1}},
$$

showing clearly that the time path of returns to each factor depends on the time-varying stocks of both variable inputs. Similarly, denoting land rents by $V_{t}=f\left(k_{t}\right)-R_{t} k_{1 t}-W_{t} k_{2 t}$, 
one similarly obtains

$$
\frac{d V_{t}}{d \tau_{1}}=-f_{1 k} \frac{d k_{t}}{d \tau_{1}}-f_{2 k} \frac{d k_{t}}{d \tau_{1}}
$$

Given the assumed parameter values, these expressions can be calculated numerically using (21) and (22).

Figure 1 plots the comparative dynamic response of factor prices to an increase in the fiscal burden on capital for the baseline parameter values specified above. This figure shows clearly that the gross factor price of capital rises unit-for-unit with the tax in the long run, asymptotically approaching 1, so that the net return to capital is unaffected. This adjustment is far from instantaneous, however, with the net return to capital recovering halfway to its externally-fixed long run equilibrium level after about 5 years. Similarly, the return to land is diminished in the long run by the tax on capital, but this adjustment also takes a comparably long time to be substantially complete. Of particular note, the figure shows that a higher fiscal burden on capital depresses the gross (and net) return to labor for as long as a decade after the policy change, an effect that disappears in the long run. Although this effect is modest, it illustrates the potential importance of transitional cross-effects of the type that, as noted above, cannot occur in static models. The magnitude of this cross effect depends on the assumed factor shares of labor and capital, as well as on the size of their adjustment cost parameters, as the next figures show.

Figure 2 shows the effects on factor prices over time resulting from an increase in the fiscal burden on labor, retaining the baseline values for all parameters. Once again, the taxed factor (labor) suffers a reduction in net return that persists for some years, though in this case the return to the long-run level is much faster because of the assumed lower cost of adjustment for labor. Land rents also adjust more quickly in this case. The cross effect on the return to capital is more marked, partly because labor's factor share is greater than that of capital. This effect is still fairly persistent, despite the relatively rapid change in the stock of labor, because of the assumed high adjustment costs for 
capital.

As a final illustration, Figure 3 varies the parameters from those assumed in Figure 1 by assuming that labor is much slower to adjust - corresponding to a value of its adjustment cost parameter equal to 55. In this case, a higher fiscal burden on capital depresses the wage significantly for a very long period, implying that much of the incidence of capital taxes falls on labor. Because labor is so slow to adjust, the fall in land rents is very much delayed, and indeed wages fall proportionally more than land rents for many of the early years after the policy change. This case might be viewed as illustrative of a situation where labor is "trapped" in a region by very high (to be more precise, by rapidly-rising) migration costs; in this case, labor becomes very similar to a second immobile factor of production for a significant period of time, even though it remains perfectly mobile in the long run - now measured in decades.

Many variations on these calculations can be made, and computer animations (see author's web site for examples) allow one to visualize the effects of changes in parameter values on the equilibrium adjustment paths of factor stocks and factor prices. Remaining with the framework of Cobb-Douglas production technologies, experimentation with different parameter values serves mainly to confirm economic common sense, as the underlying model is very neoclassical in nature. The finding of greatest importance, central to exploitation of dynamic rather than static modeling, is already illustrated by a comparison of Figures 1 and 3: factors with nearly-linear adjustment cost functions respond very quickly to changes in fiscal treatment, while highly convex adjustment cost functions lead to protracted adjustments. The explicit modeling of adjustment costs thus permits empirically meaningful distinctions to be drawn between "highly mobile" and "highly immobile" factors of production. The model demonstrates that the owners of relatively or completely immobile factors of production cannot gain much, in a fiscal incidence sense, from imposing fiscal burdens on highly mobile resources, a result that has obvious predictive implications regarding equilibrium fiscal structures in open economies. Clearly, 
there remain many avenues for useful further analysis, perhaps calibrated to more general production technologies (e.g., CES) and to particular policy scenarios.

\section{Conclusion}

To summarize, the preceding analysis has shown how local fiscal policy, applied to one of two imperfectly mobile factors of production, affects the dynamic equilibrium allocation of both. The system adjusts gradually to a long-run equilibrium, with effects on equilibrium allocations that depend on the local production technology, including complementarity or substitutability of the mobile factors. The speed with which this adjustment occurs, for each of the two factors of production, depends on the costs of adjustment for both.

Since gross factor prices are determined by factor supplies, the dynamic impacts of fiscal policy on the returns to local mobile and immobile factors are readily determined from the time paths of factor stocks. For example, an increase in the tax on one factor has no immediate impact on factor allocations and thus no immediate impact on the gross return to any factor of production. The net return to the more heavily taxed factor thus initially falls by the amount of the increase in tax, while net returns to other factors are unaffected. In the long run, the gross return to the more heavily taxed factor rises sufficiently to restore its net return to its externally-given value. The impacts of the higher tax on gross and net returns to the other mobile resource and to the immobile factor(s) depend upon complement/substitute relationships in production. If one of the mobile factors is capital and the other is labor, the two factors are complementary inputs according to empirical studies. In this case, a tax on one input is partially shifted to the other during the transition to a new steady-state equilibrium, a transitional impact that has no counterpart in static equilibrium models.

If the process of adjustment to higher taxes is slow, the net return to the more heavily- 
taxed factor, as well as to a complementary factor, can be substantially depressed for a long period of time. If instead this process is fast, the net return quickly approaches the externally-determined level. There may then be equally rapid impacts on the amount of the other mobile resource and on the gross and net returns to it and to the immobile factor.

There are many potential applications and extensions of this analysis, of which only a few are mentioned for the sake of brevity.

First, because transition periods can be of substantial duration, analyses that focus only on very long effects of policy changes omit important considerations. In static models of the type presented in section 2 , taxes on mobile resources can only harm the interests of immobile factor owners. If the proceeds of a tax on imperfectly mobile capital or labor are paid to immobile factor owners, however, it is quite possible for them to benefit, in present value terms, even though they are harmed in the long run. For instance, a tax on capital may be borne substantially by capital and labor, and only to a slight degree by immobile factor owners, for a period of 5-10 years. The "short run" gains may well outweigh the long run harm, for reasonable discount rates. Indeed, one can show that the interests of immobile factor owners are best served by introducing at least a small positive tax rate on mobile factors of production, as has been previously shown in the single-factor case (Wildasin 2003).

Second, from the perspective of political economy, note that the owners of imperfectly mobile factors have incentives to influence local policies even though these policies can have no effect on net factor returns in the long run. This is essentially a corollary of the preceding remark, as the gains to immobile factor owners from taxes on imperfectly mobile resources are achieved at the expense of the owners of "trapped" factors of production that can only escape in the long run. Participation and intensity of interest in the local political process depend on speeds of adjustment in response to policies, with many combinations of "voice" and "exit" (see Hirschman 1970) possible depending on 
production and adjustment cost technologies.

Third, from an economic development viewpoint, dynamic analysis is clearly crucial to an understanding of the time frame over which tax incentives or other development policies can be expected to work. The preceding analysis has demonstrated the interdependent dynamic responses of each of two mobile resources to the fiscal treatment of either of them. As an illustration, the analysis has shed light on how, when and to what degree more favorable fiscal treatment of imperfectly mobile business capital may benefit workers. Similar analyses could be undertaken to explore other policies, such as fiscal preferences for high-skilled workers and their impact on investment in non-human capital or on the demand for low-skilled workers.

Fourth, the analysis identifies important empirical parameters that influence the dynamic impacts of tax policies. These include adjustment cost functions for potentially mobile factors of production. Studies such as those of Decressin and Fatas (1995), who estimate that interregional labor force adjustments in Europe occur at about half the speed of similar adjustments in the US, can assist in determining the proper specification and parameterization of such functions. Comparatively few empirical analyses have been directed to such questions to date, but there is scope for fruitful application of the findings of future investigations of this type.

Finally, it is worth recalling that simultaneous flows of labor and capital have accompanied the development of important economic regions over widely varying time scales. Authors such as Hatton and Williamson (1994) have documented the long-term flows of labor and capital from the Old World to the New World and their important effects on output, factor prices, and the distribution of income in both regions during the nineteenth century. Migration by skilled workers has been estimated by Barrett et al. (2002)) to have had large impacts on economic growth and the distribution of income in the Irish economy prior to the recent economic downturn. The twentieth century in the US has witnessed South/North (early-mid century), East/West (century-long), Rust 
Belt/Sun Belt (latter decades), and rural/urban (century-long) flows of labor and capital among major regions. The growth and decline of particular agglomerations, such as New York, Detroit, St. Louis, or Atlanta are records of simultaneous flows of both labor and capital. These dynamic adjustment processes are ongoing and reflect underlying complementarities in production and the resulting partial synchronization of migration and investment flows. Exactly how the costs of labor and capital stock adjustment interact to produce observed flows has not so far been investigated empirically, but this simultaneous adjustment process, stemming ultimately from production complementarities, must also give rise to "policy complementarities" in which, for example, the provision of local educational services and local tax policies affect the attractiveness of a region for workers and for complementary investments in non-human capital, and the tax treatment of local business and the provision of public infrastructure affect the profitability of business investment and the employment conditions for local workers. Comparative dynamic analysis can provide a framework with which to explore such issues. 


\section{Appendix: The Method of Variational Equations}

This appendix provides a concise informal discussion of variational equations. It draws upon Hartman (1964, Theorem 3.1, pp. 95-96). See also Boadway (1979).

Suppose that the evolution of a vector $x(t)$ is described by the system

$$
\dot{x}=f(x(t), \theta)
$$

where $\theta$ is some parameter of the system. A solution to this system is a vector $\xi(t, \theta)$, depending on time $t$ and on the parameter $\theta$. An equilibrium (equivalently, rest point or steady state) is a vector $x^{*}$ such that $f\left(x^{*}, \theta\right)=0$. For present purposes, existence of a "well-behaved" solution to (A.1) is assumed for some value of $\theta$ and for some relevant initial conditions. Specifically, sufficient smoothness and convergence of a solution to an equilibrium is assumed.

The problem of interest is to understand the dependence of the solution $\xi(t, \theta)$ on the parameter $\theta$. A first-order approximation of the rate of change of the solution with respect to the parameter is given by the partial derivative $\partial \xi(t, \theta) / \partial \theta$ which, in general, is time-varying. Since $\xi(t, \theta)$ satisfies (A.1) for all values of $\theta$,

$$
\dot{\xi}(t, \theta) \equiv f(\xi(t, \theta), \theta)
$$

Differentiating with respect to $\theta$,

$$
\frac{\partial \dot{\xi}(t, \theta)}{\partial \theta}=f_{x}(\xi(t, \theta), \theta) \frac{\partial \xi(t, \theta)}{\partial \theta}+f_{\theta}(\xi(t, \theta))
$$

where $f_{x}$ and $f_{\theta}$ denote partial derivatives of $f$ with respect to $x$ and $\theta$, resp.

Assuming that the system (A.1) is initially in equilibrium, i.e., $\dot{x}(t)=0$ and $x(t)=x^{*}$, 
(A.3) can be written as system of linear differential equations with constant coefficients,

$$
\dot{y}=f_{x}\left(x^{*}, \theta\right) y+f_{\theta}\left(x^{*}, \theta\right)
$$

where, for notational convenience, $y(t, \theta)$ denotes $\partial \xi(t, \theta) / \partial \theta$. Such systems can be solved explicitly for $y(t)$, the time-varying rate of change of the solution of the system (A.1) with respect to the parameter $\theta$.

In the analysis of Section 3, the state of the system depends on the capital stock $k(t)$ and on the shadow value of capital. Differentiation of equations (3) and (9) produces a system of two first-order differential equations (13) and (14) in $k_{t}$ and $\lambda_{t}$ which, with some manipulation and standard relabeling, can be equivalently expressed as a system of two second-order differential equations in $k_{t}$ alone, as described in the text. When evaluated at a steady state, this system has constant coefficients and is (relatively) easily solved. 


\section{References}

Aaron, H. J. (1975), Who Pays the Property Tax? A New View (Washington: Brookings Institution).

Barrett, A., J. Fitzgerald, and B. Nolan (2002),"Earnings Inequality, Returns to Education and Immigration into Ireland," Labour Economics 9, 655-680.

Becker, D. and M. Rauscher (2007), "Fiscal Competition in Space and Time: An Endogenous Growth Approach", CESifo Working Paper No. 2048.

Boadway, R. (1979), "Long-run Tax Incidence: A Comparative Dynamic Approach," Review of Economic Studies 46, 505-511.

Bradford, D.F. (1978), "Factor Prices May Be Constant but Factor Returns Are Not", Economics Letters 1, 199-203.

Brochner, J., J. Jensen, P. Svensson, and P.B. Sorensen (2007), "The Dilemmas of Tax Coordination in the Enlarged European Union", CESifo Economic Studies 53, 561-595;

Brueckner, J.K. (2000), "Welfare Reform and the Race to the Bottom: Theory and Evidence," Southern Economic Journal 66, 505-525.

Brueckner, J.K. (2003), "Strategic Interaction Among Governments: An Overview of Empirical Studies," International Regional Science Review 26, 175-188.

Brueckner, J.K. and L.A. Saavedra (2001), "Do Local Governments Engage in Strategic Tax Competition?" National Tax Journal 54, 203-230.

Buettner, T. (2001), "Local Business Taxation and Competition for Capital: The Choice of the Tax Rate", Regional Science and Urban Economics 31, 215-245.

Chirinko R. and D.J. Wilson (2007), "State Investment Tax Incentives: What Are the Facts?" National Tax Association Annual Conference Proceedings, 36-44.

Chirinko, R. and D.J. Wilson (2008), "State investment tax incentives: A zero-sum 
game?", Journal of Public Economics 92, 2362-2384.

Conway, K.S. and A. J. Houtenville (2001), "Elderly Migration and State Fiscal Policy: Evidence from the 1990 Census Migration Flows," National Tax Journal 54, 103-24.

de Bartolome, C.M (1997), "Slow Adjustment and the Level of Government Spending", Journal of Urban Economics 42, 285-311.

Decressin, J. and A. Fatás (1995), "Regional Labor Market Dynamics in Europe," European Economic Review 39, 1627-1655.

Devereux,M. P., and R. Griffith (2002), "The Impact of Corporate Taxation on the Location of Capital: A Review," Swedish Economic Policy Review 9, 79-102.

Devereux, M. P., R. Griffith and A. Klemm (2002). "Corporate Income Tax Reform and International Tax Competition." Economic Policy 35 (October): 451-488.

Docquier, F. and H. Rapoport (2008), "Skilled migration: The perspective of developing countries", in J. Bhagwati and G. Hanson (eds.), Skilled Migration (Oxford: Oxford University Press).

Hartman, P. (1964) Ordinary Differential Equations (New York: Wiley).

Hatton, T.J. and J.G. Williamson (1994), "International migration 1850-1939; An economic survey," in T.J. Hatton and J.G. Williamson (eds.), Migration and the International Labor Market 1850-1939, Routledge, London, 1994, 3-54.

Hayashi, F. (1982), 'Tobin's Marginal q and Average q: A Neoclassical Interpretation," Econometrica 50 213-224.

Huizinga, H. and G. Nicodème (2004), "Are international deposits tax-driven?" Journal of Public Economics Volume 88, 1093-1118.

Kehoe, P.J. (1989), "Policy cooperation among benevolent governments may be undesirable," Review of Economic Studies 56, 289-296.

Makris, M. (2009), "Intertemporal Capital Tax Externalities and the 'Race to the Bot- 
tom", unpublished.

Mieszkowski, P. (1972), "The Property Tax: An Excise Tax or a Profits Tax?", Journal of Public Economics 1, 73-96.

Nechyba, T. (1999), "School finance induced migration and stratification patterns: the impact of private school vouchers," Journal of Public Economic Theory 1, 5-50.

Nechyba, T. (2000), "Mobility, targeting, and private school vouchers," American Economic Review 90, 130-146.

Peterson, P.E. and M.C. Rom (1990), Welfare Magnets: A New Case for a National Standard (Washington: Brookings).

Sorensen, P. B. (2000), "The Case for International Tax Coordination Reconsidered," Economic Policy 31, 429-472.

Sorensen, P.B. (2004), "International tax coordination: regionalism versus globalism," Journal of Public Economics 88, 1187-1214.

Tiebout, C. M. (1956), "A Pure Theory of Local Public Expenditures", Journal of Political Economy.

Wildasin, D. (2003), "Fiscal Competition in Space and Time," Journal of Public Economics, 87, 2003, 2571-2588.

Wildasin, D.E. (2006a), "Fiscal Competition", in Barry Weingast and Donald Wittman (eds.), Oxford Handbook of Political Economy (Oxford: Oxford University Press, 2006), 502-520.

Wildasin, D.E. (2006b), "Global Competition for Mobile Resources: Implications for Equity, Efficiency, and Political Economy," CESifo Economic Studies 52, 2006, 61-111.

Wildasin, D.E. (2008), "Public Pensions and Demographic Change in Developed Countries: Fertility Bust and Migration Boom?", in J. Bhagwati and G. Hanson (eds.), Skilled Migration (Oxford: Oxford University Press). 
Wildasin, D.E. and J.D. Wilson (1996) "Imperfect Mobility and Local Government Behavior in an Overlapping-Generations Model," Journal of Public Economics 60(2), 177198.

Wilson, J.D. (1995), "Mobile Labor, Multiple Tax Instruments, and Tax Competition," Journal of Urban Economics 38, 333-356.

Wilson, J.D. (1999) "Theories of Tax Competition," National Tax Journal 52, 269-304.

Wilson, J.D. and D.E. Wildasin (2004), "Capital Tax Competition: Bane or Boon?" Journal of Public Economics 88, 1065-1091.

Zodrow, G. (2007), "The Property Tax Incidence Debate and the Mix of State and Local Finance of Local Public Expenditures", CESifo Economic Studies 53, 495-521.

Zodrow, G. and P. M. Mieszkowski (1986), "Pigou, Tiebout, Property Taxation and the Underprovision of Local Public Goods" Journal of Urban Economics . 
Figure 1

Dynamic Effects of Capital Tax Increase on Factor Returns:

Baseline Parameter Values

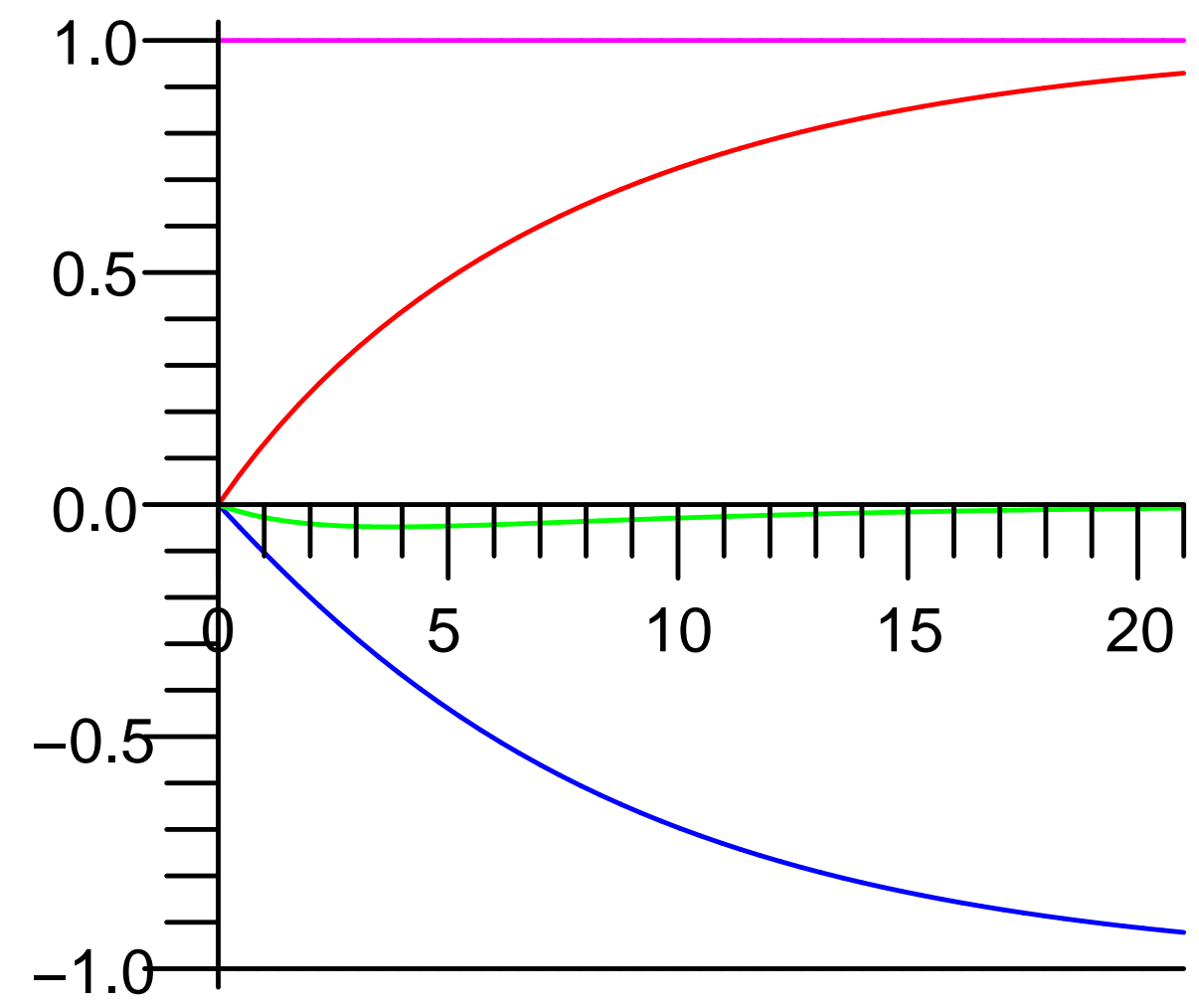

Capital Return

Capital Return, Asymp.

Wage

Rent

Rent, Asymptote 
Figure 2

Dynamic Effects of Labor Tax Increase on Factor Returns: Baseline Parameter Values

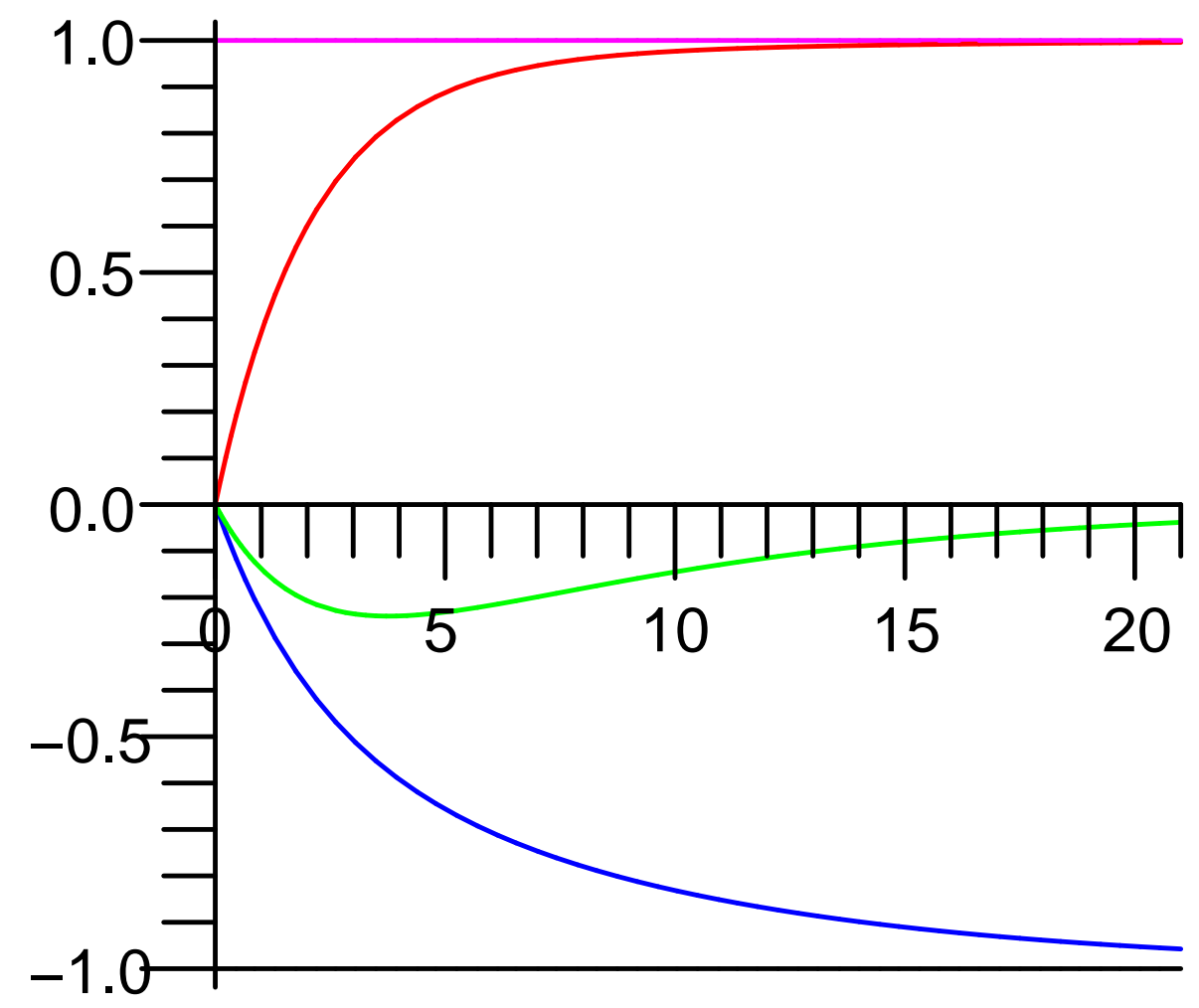

Wage

Wage, Asymptote

Capital Return

Rent

Rent, Asymptote 
Figure 3

Dynamic Effects of Capital Tax Increase on Factor Returns:

Labor Adjustment Cost Parameter $=55$

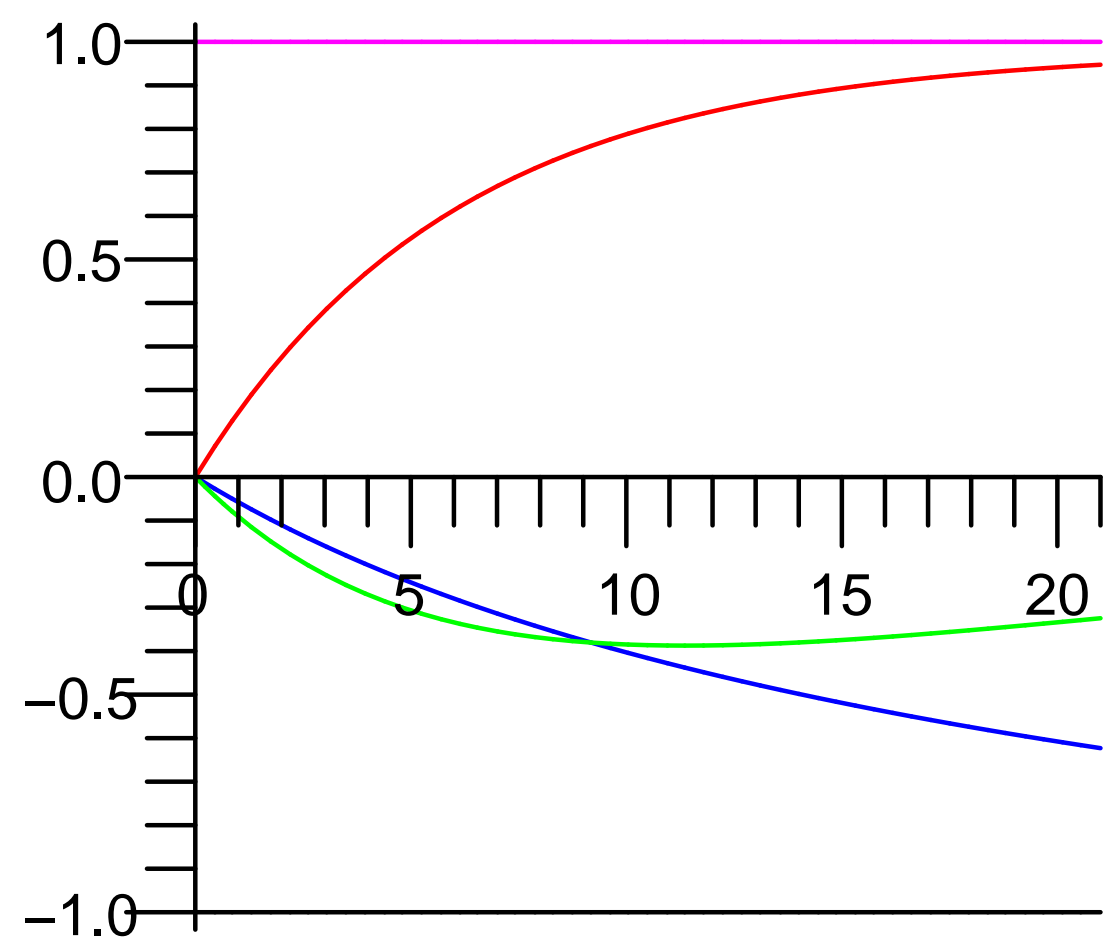

Capital Return

Capital Return, Asymp.

Wage

Rent

Rent, Asymptote 